\title{
HUNTING CRIMES IN LEBANON FACING GOVERNMENT AND PUBLIC INDIFFERENCE
}

Shantal Maroun, student of the $4^{\text {th }}$ edition of the Master in Animal Law and Society - UAB

\section{SUMMARY}

I- Introduction

II- Facts:

1- Birds' Massacre

2- Wild Animals

3- The government

III-Conclusion 


\section{Introduction:}

"Lebanese Woman Changes the Face of the Gaming Industry in the Middle East and the Launching of Survival Race: Life or Power Plants on IOS and Android. From Lebanon to the world! The launching of an action-packed new mobile racing game, with two unlikely heroes and climate change awareness message"

"Quality of math and science education: Lebanon 4th in Math \& Science education out of 144 countries: The World Economic Forum's 2013 Global IT Report, ranked Lebanon in the top 5 countries of the World for Math and Science education. Out of the 144 countries surveyed, Lebanon came 4th after Singapore, Finland and Belgium. A ranking that Lebanese people should be really proud of!"

These Lebanese achievements may look very interesting and carry a lot of hope and pride to Lebanese citizens, but unfortunately nobody talks about them, nobody shares them on social media, probably because people do not read that kind of news and information, others may read and find them too boring to share with family, friends and acquaintances. Considering Facebook as the social media example for this article, it is surprising yet deceiving how with time, it turned from a simple page to share special moments, random thoughts and social interactions, to a tool used to promote acts of cruelty, indifference and ignorance. 


\section{Facts:}

\section{Birds' Massacre:}

Lebanon is located in one of the world's most important corridors for bird migration. It is situated centrally on the Eastern Eurasian-African migratory bird flyway, which is used every year by several million European migratory birds "en route" to their winter quarters in Africa and on prenuptial flight to their European breeding grounds. Yet, every year many birds, and by many we mean a significantly large number, are killed by hunters who are either unaware or indifferent to the country's poorly enforced hunting ban and to the crime they are committing day after day against nature, biodiversity, environment and most importantly again those poor animals that are being massacred inhumanely. Lies here even a saddest fact, the public support that the hunters are getting and the government ignorance that is leading the country to a chaos.

Everyday Facebook is full of updates concerning the hunting activities, hunters of all ages showing off with their immense catches picturing them as trophies and achievements. The fashion is that the hunters seem to boast about their kills, and the bigger, the rarer and the larger the number the better as far as they are concerned. And what days have we come to when a video of the Lebanese singer Hiba Tawaji fascinating the jury in the $T V$ show in France "The voice" with her authentic Lebanese voice gets few 
likes from people, while a single picture of a hunter posing with dead animals, all smiling and proud, gets hundreds of likes and comments such as: Glorious or divine. Are we living in a world where massacred creatures and cruel acts are considered glorious and divine? Or did suddenly the Lebanese people lose their sense of humanity?

According to the report of the hunting of migrant birds in Lebanon affected species and their conservation status in the EU, around 143 species of birds are affected by poaching. The Lebanese Environment Movement (LEM) with support from the Committee Against Bird Slaughter (CABS) monitored a large number of hunter's Facebook pages for months and collected more than 700 photographs as proof of poaching of European migrants birds. A total of 13,100 birds are shown in the photos, of which 11,123 can be identified at species level.

Knowing that Lebanon joined the Agreement on the Conservation of African-Eurasian Migratory Water birds (AEWA) in 1/12/2012, protected water birds remain one of the largest targets for poachers without any local or international intervention. Storks are the major victims of massacres, killed by dozens with sometimes an elimination of a complete flock. Many Lebanese consider storks as a "tasty" meal, and encourage their hunting. Pelicans are also a large target for poachers. Other targeted water birds include cranes, herons and northern lapwings. Cases of shot greater flamingos have also been reported. Species shot are of a large variety including among others: buzzards, eagles, falcons and 
harriers... Not to forget one of the most shocking cases was that of a killed Egyptian vulture which is listed as endangered by the International Union for Conservation of Nature (IUCN).

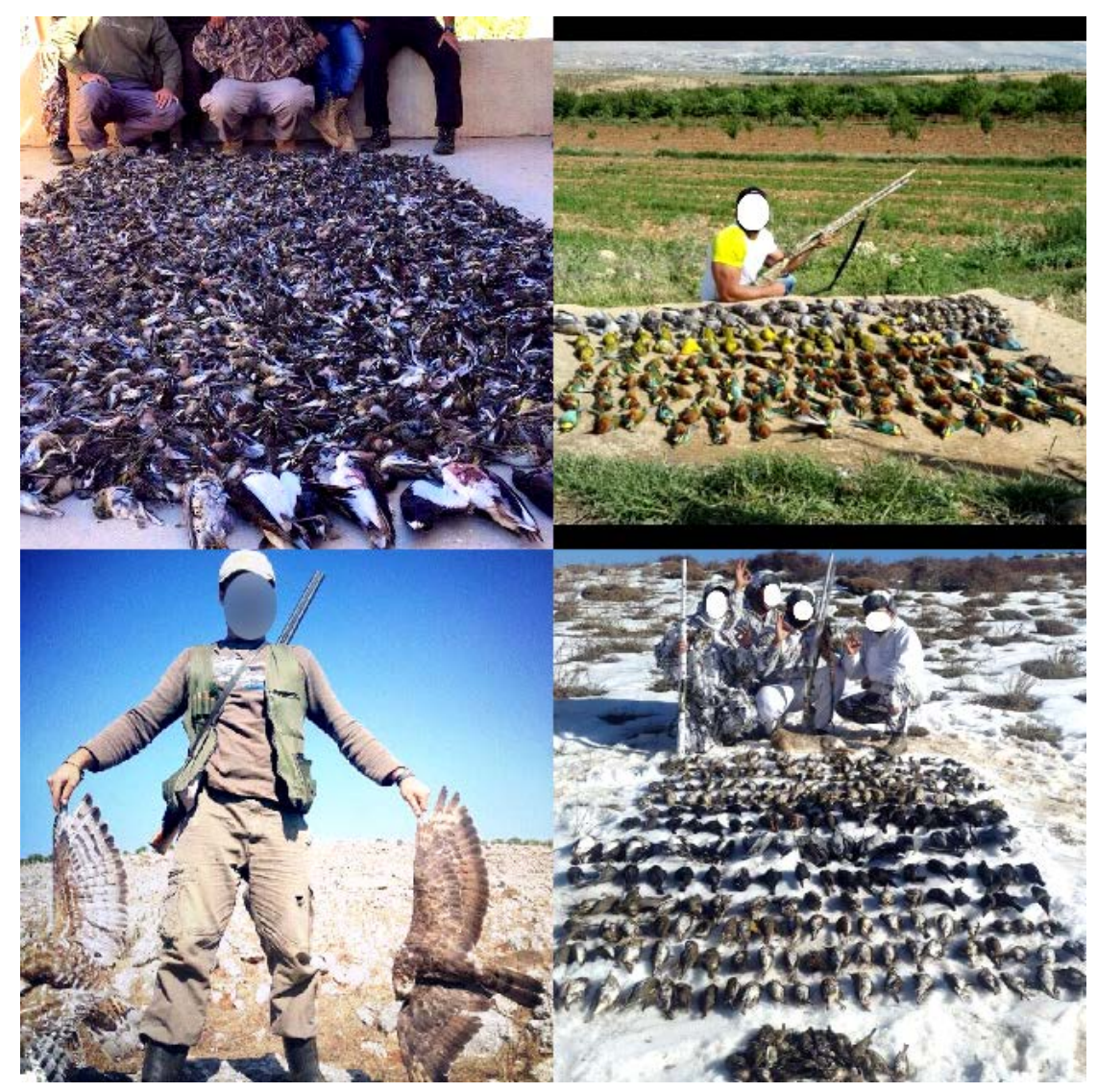

\section{Wildlife:}

Although the birds hunting forms the biggest part of the Lebanese massacre against nature, animals and environment, it is really important that we do not forget the other wild animals that, just by not being birds does not mean they are surviving the hunters crave to hunt and kill them. 
As mentioned in the birds section, one does not need to go through a lot of researches to find out what is happening, which animals are being killed, how many and what are the methods used. Everything is being posted on social media especially the Facebook pages. The spectrum of wild animals includes wild boars, foxes, wild rabbits, badgers hyenas and many others.

In one single photograph of a hunter showing off his recent catch, we can identify almost 25 wild rabbits and 10 badgers all hanged by the car's windows or laying on top of it. And of course, what is left from the car space is always reserved for hundreds of killed birds. In one other picture, 3 guys proudly standing and holding inhumanely a dead wild boar covered with his blood. Not afraid, nor ashamed to publish such kind of photograph, not only because they are indifferent but rather because they know that Facebook users, that practically represent the society, will be cheering for them and giving them credits for what they've done. 


\section{dA derecho ANIMAL la web center de los animales con derecho}

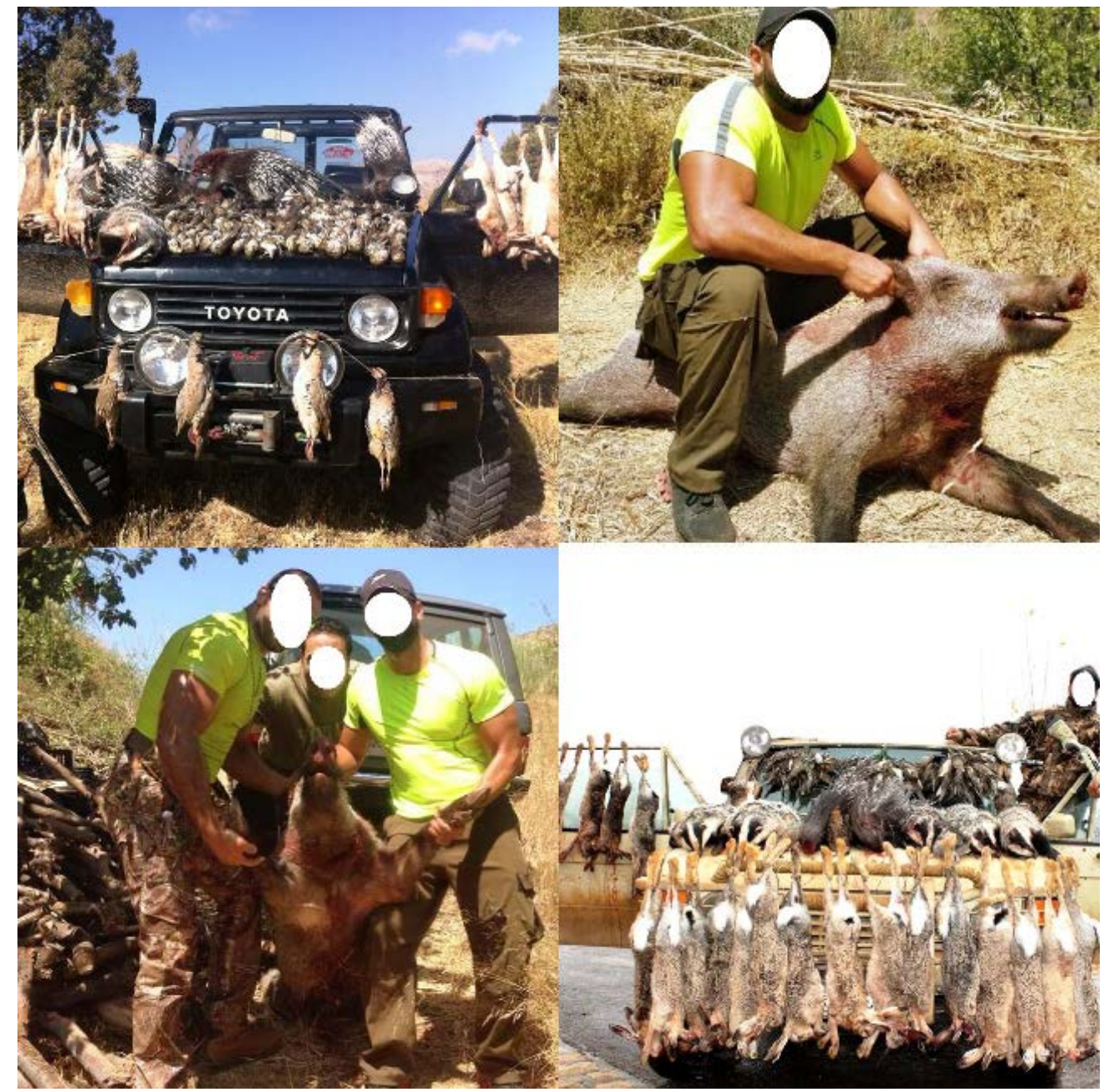

\section{The government:}

Knowing that we could go all day all night enumerating all the hunting crimes whether against birds or other wildlife animals, one new question adds up here: Why isn't the government doing anything to prohibit such nature violations? In 1995, a law was passed that banned hunting altogether. This law was modified in 2004, under then- President Emile Lahoud, to regulate hunting and impose penalties in case of any law 
infringement. So what happened to this law and why is it not being enforced?

According to the law 580/2004:

- Article 3: The Minister of environment shall specify the opening date and the end of the hunting season and times that are allowed to hunt during which, based on the proposal of the Board, shall be prevented to hunt during the reproduction season of animals and birds and during the transit towards their breeding grounds...

- Article 6: It is prohibited to anyone to hunt outside the permitted hunting times and the hunter must be in possession of a hunting license given to him by the ministry of environment following precise characteristics...

- Article 8: It is strictly prohibited to hunt in the cities, villages, hiking spots, nature reserves and all places classified as heritage...it is also prohibited to display the preys caught on cars and on public roads.

- Article 14: Shall be punished by imprisonment for up to a month and a fine equivalent to five hundred thousand Lebanese pounds or either of them, and by withdrawing the hunting license from one to three years duration anyone caught hunting outside the duration set for hunting season...

- Article 15: Shall be punished by imprisonment for up to a month and a fine equivalent to five hundred thousand Lebanese pounds or either of them, and by withdrawing the hunting license from one to three years duration, as well as the confiscation of all weapons, tools, machines and devices, anyone caught hunting without a valid license, or using prohibited methods of hunting, tools, machines and devices, or anyone hunting birds considered useful for the environment and listed prohibited caught. 
More articles come along with this law, but unfortunately there is no inspection, no regulation and no enforcement. Hunters are committing law violations every day and there are no judges, no ministry and no government to control.

\section{Conclusion:}

These facts may or may not interest or capture the attention of everyone to start looking at the laws violation giving the fact that we live in a country of disorder and total confusion of priorities. But let's talk ethically wise, where does a society stands on an ethical level when it cheers and applauds for hunters shooting here and there thousands of birds, eradicating species, ruining the biodiversity system and promoting cruelty against animals? How much of ignorance and denial of a sad shameful truth, can this society carry when thinking that massacring animals and showing off the massive crime, defines a person as a "real man"? When will it be ready to open up to this reality, detect the wrong side of it and start changing for the better? Probably never! Probably when the nature is out of those beautiful animals, people might as well start hunting each other, something they are already doing, lacking any sign of moralities and humanity. 